\title{
CIRI-CIRI ADVERBIA BAHASA MELAYU JAMBI DI KELURAHAN TANJUNG RADEN KECAMATAN DANAU TELUK KOTA JAMBI (KAJIAN MORFOSINTAKSIS)
}

\author{
Sainil Amral ${ }^{1}$, Retno Wahyu Ningsih ${ }^{2}$ \\ Program Studi Pendidikan Bahasa dan Sastra Indonesia \\ Fakultas Keguruan dan Ilmu Pendidikan Universitas Batanghari \\ Jambi \\ amralsainil@gmail.com \\ retnowahyuningsih43@gmail.com
}

\begin{abstract}
This research aims to describe adverbial of Jambi Malay language in Tanjung Raden districk Danau Teluk subdistrict Jambi city. This research uses qualitative descriptive methods. The data is collected through observation and interview. In this study, the data is in the form of Adverbs which are derived from 6 informants. The sample is natice speaker of Jambi Malay language in Tanjung Raden districk Danau Teluk subdistrict Jambi city. The data are analyzed by using method of distribution analysis. The results of this research show that the characteristic of Jambi Malay language adverbs include; the characteristic of morphological adverbc which can be seen from the words 'konyok' which means not because that word does not indicate a hallmark of a word that is undergoing of morphological process or cannot join the affix particle. Meanwhile the characteristic of syntactical adverb can be seen from the word 'be' which means 'just'. From the position of the structure, it can be concluded that the attitude of adverb (b) always follows the word that is explained.
\end{abstract}

Keywords: Adverb, Jambi Malay Language, Morphosyntax

\footnotetext{
${ }^{1}$ Dosen Program Studi Pendidikan Bahasa dan Sastra Indonesia, Fakultas Keguruan dan Ilmu Pendidikan, Universitas Batanghari Jambi

${ }^{2}$ Mahasiswa Program Studi Pendidikan Bahasa dan Sastra Indonesia, Fakultas Keguruan dan Ilmu Pendidikan, Universitas Batanghari Jambi

Ciri-ciri Adverbia Bahasa Melayu Jambi di Kelurahan Tanjung Raden Kecamatan Danau Teluk Kota Jambi (Kajian Morfosintaksis)
} 


\section{PENDAHULUAN}

"Negara Indonesia didiami oleh suku bangsa yang sangat beragam yang memiliki bahasa yang beragam pula. Walaupun telah ada, bahasa Indonesia sebagai bahasa nasional, tetapi bahasabahasa daerah yang beragam itu masih tetap dipakai sebagai alat komunikasi di daerah-daerah yang bersangkutan (Husin dkk. 1986: 1)." Bahasa daerah itu juga dipelihara oleh negara sebagaimana tercantum dalam penjelasan UUD 1945, Bab XV, pasal 36 yang menyatakan bahwa bahasa daerah yang masih dipakai sebagai alat penghubungan oleh masyarakat bahasa setempat dibina dan dipelihara oleh negara. Berdasarkan pendapat ahli di atas bahwa bahasa daerah perlu dipelihara dan dibina, hal inilah yang melatarbelakangi bahasa daerah menarik untuk dikaji.

Salah satu bahasa daerah tersebut adalah Bahasa Melayu Jambi. Bahasa Melayu Jambi merupakan bahasa daerah yang paling dominan digunakan di Provinsi Jambi. Bahasa Melayu Jambi merupakan suatu bahasa dari suku bangsa yang memegang peranan penting dalam sejarah Sumatera (Husin dkk. 1986: 1). Senada dengan hal tersebut Rahima (2019:9) menjelaskan bahwa secara historis masyarakat Jambi termasuk kelompok pemakai bahasa Melayu. Sampai saat ini pada kenyataannya, bahasa Melayu Jambi dipakai untuk berkomunikasi antarsuku dan warga masyarakat secara formal dan nonformal. Menurut Husin dkk (1986: 2), "Bahasa Melayu Jambi bukanlah bahasa daerah satu-satunya yang digunakan oleh penduduk Provinsi Jambi, tetapi terdapat pula beberapa bahasa lain dengan penutur yang cukup banyak. Di antaranya mencakup: (1) bahasa Melayu Jambi, (2) bahasa Batin, (3) bahasa Penghulu, (4) bahasa Kubu, (5) bahasa Bajau, dan (6) bahasa Kerinci."

Bahasa Melayu Jambi merupakan bahasa yang penyebaran atau penuturnya terluas, karena hampir mencakup semua Kabupaten yang ada di Provinsi Jambi. Bahasa Melayu Jambi digunakan oleh masyarakat untuk berkomunikasi dalam keseharian baik acara formal maupun non formal yang bersifat kedaerahan. Menurut Rahima (2002:1) fakta sosial telah menunjukkan bahwa bahasa Melayu Jambi juga dipakai di ranah formal yakni untuk menyampaikan pesan-pesan pembangunan kepada masyarakat yang ada di Provinsi Jambi. Sedangkan secara nonformal bahasa Melayu Jambi digunakan sebagai alat komunikasi antarsuku lain yang ada di daerah Jambi. Masing-masing daerah memiliki ciri khas bahasanya. Namun dalam keanekaragaman tersebut menjadikan sebagian besar masyarakat penutur bahasa Melayu Jambi menggunakan bahasa Melayu Jambi dalam berinteraksi sehari-hari dengan warga yang berbeda bahasa .

Bahasa Melayu Jambi berperan penting memberi sumbangan terhadap perkembangan dan pertumbuhan bahasa Indonesia, terutama dalam segi kosakata, pada kelas kata adverbial. Hal inilah yang menjadi alasan bahwa penelitian mengenai ciri-ciri adverbia bahasa Melayu Jambi khusunya bahasa Melayu Jambi di Kelurahan Tanjung Raden Seberang Kota Jambi, penting untuk dilakukan.

"Adverbia dapat dijelaskan sebagai kategori yang dapat mendampingi adjektiva, numeralia, atau preposisi dalam kontruksi sintaksis (Kridalaksana, 1990:79)." Singkatnya adverbia biasa dikatakan sebagai kata keterangan, yang dipakai dalam bahasa. Adverbia merupakan salah satu kategori kelas kata yang cukup rumit untuk 
mengidentifikasikannya. Karena, sulit dalam menentukan kejati-dirian kata tersebut.

Penelitian ini juga sebagai salah satu langkah untuk mengembangkan tata bahasa Melayu Jambi, karena bahasa Melayu Jambi belum mempunyai kamus besar bahasa Melayu Jambi. Bahwa sampai saat ini belum atau jarang ada pembakuan atau standarisasi tata bahasa Melayu Jambi, untuk kelengkapan itu diperlukan penelitian-penelitian ketatabahasaan salah satunya adalah penelitian kelas kata adverbia.

"Kecenderungan ini sangat memungkinkan bahasa Melayu Jambi dianggap bahasa kampung, sehingga dikhawatirkan orang muda Seberang merasa tidak percaya diri memperlihatkan identitas daerah mereka (Adwin, 2013:3-4)". Berdasarkan pendapat di atas, dapat disimpulkan bahasa Melayu Jambi saat ini cenderung kurang bermartabat sehingga para pemakainya merasa tidak bangga atau rendah diri. Salah satu cara untuk pemartabatan bahasa Melayu Jambi yaitu dengan melakukan penelitian yang hasilnya dapat dipublikasikan atau disebarkan untuk meningkatkan pemahaman masyarakat terhadap bahasa Melayu Jambi.

Berdasarkan pengamatan yang telah dilakukan, diketahui bahwa bahasa Melayu Jambi Kelurahan Tanjung Raden memiliki beberapa kosakata yang sudah jarang digunakan seperti moyo 'tidak' dan entan 'ada'. Oleh Karena itu penelitian ini penting untuk dilakukan untuk permartahanan bahasa atau pelestarian bahasa terhadap Bahasa Melayu Jambi.

Tanjung Raden merupakan salah satu Kelurahan yang berada di Kecamatan Danau Teluk Kota Jambi, daerah yang berada di seberang Sungai
Batanghari tepatnya di Seberang Pasar Angso Duo Kota Jambi. Kelurahan Tanjung Raden beralamat di Jalan KH. M. Saleh Kecamatan Danau Teluk Kota Jambi dengan jarah tempuh dari pusat Kota Jambi sekitar $6 \mathrm{Km}$. Jumlah penduduk keseluruhan Kelurahan Tanjung Raden 3,167 jiwa (Data tahun 2013).

Berdasarkan latar belakang tersebut, dapat diidentifikasikan masalah penelitian terkait kelas kata adverbia. Menurut Kridalaksana (79:1990) terdapat 4 bagian dalam kelas kata adverbia sebagai berikut.

1. Bentuk adverbia, terdiri dari monomorfemis (bentuk dasar) dan Polimorfemis (bentuk turunan).

2. Ciri-ciri adverbia, terdiri dari ciri adverbia intraklausal (morfologi) dan sintaksisnya (ekstraklausal).

3. Fungsi adverbia, terdiri dari adverbia sebagai penanda aspek, adverbia sebagai penanda modalitas, adverbia sebagai penanda kuantitas, dan adverbia sebagai penanda kualitas

4. Makna adverbia.

Penelitian ini memfokuskan permasalahannya pada ciri-ciri adverbia bahasa Melayu Jambi di Kelurahan Tanjung Raden Kecamatan Danau Teluk Kota Jambi. Penelitian ini bertujuan untuk menjawab pertanyaan penelitian sebagai berikut.

1. Bagaimanakah ciri ciri adverbia morfologi bahasa Melayu Jambi di Kelurahan Tanjung Raden Kecamatan Danau Teluk Kota Jambi?

2. Bagaimanakah ciri-ciri adverbia sintaksis bahasa Melayu Jambi di Kelurahan Tanjung Raden Kecamatan Danau Teluk Kota Jambi?

\section{Kajian Pustaka}

Menurut Muhammad (2011:5), "Bahasa merupakan sistem tanda bunyi 
ujaran yang bersifat arbitrer atau sewenang-wenang." Pendapat ini menyatakan bahwa bahasa merupakan suatu kesatuan tanda bunyi yang dihasilkan manusia melalui ujaran yang bersifat manasuka. Parera (1987: 13) menyatakan bahwa, "Bahasa merupakan satu produk yang terdiri dari unsur bunyi atau ekspresi bunyi dan makna." menurut Chaer (2011: 1), "Bahasa adalah suatu sistem lambang bunyi, bersifat arbitrer, digunakan oleh suatu masyarakat tutur untuk bekerja sama, berkomunikasi dan mengidentifikasi diri."

Berdasarkan teori yang dijabarkan di atas, dapat disimpulkan bahasa adalah sistem lambang bunyi berupa simbolsimbol yang diucapkan oleh alat bunyi manusia, digunakan sebagai alat bekomunikasi masyarakat untuk menyampaikan gagasan atau pendapat yang memiliki makna, menonjolkan kejatidirian suatu bahasa tersebut, dan bersifat arbiter atau mana suka. Tentunya pendapat para ahli yang telah dikemukakan sebelumya mempunyai berbagai perbedaan di dalam pengertian bahasa.

Secara umum fungsi bahasa adalah sebagai alat komunikasi, tetapi para ahli juga memaparkan fungsi bahasa dalam beberapa definisi. Rofii dan Hasibuan (2019: 17) menyatakan bahwa fungsi bahasa yang paling mendasar ialah sebagai alat komunikasi. Menurut Pateda (1994: 12), "Fungsi bahasa terbagi menjadi dua yaitu (1) sebagai alat berkomunikasi, (2) sebagai alat kebudayaan." Dari konsep tersebut dapat diartikan fungsi bahasa ialah alat yang dijadikan sebagai penghubung sesama masyarakat yang dapat pula untuk menyatakan pikiran yang dapat dijadikan mewariskan kebudayaan kita kepada orang lain baik itu lisan maupun secara tulisan.

\section{Menurut Chaer} bahwa,"Tataran bahasa terdiri pula dari beberapa subsistem yaitu, subsistem fonologi, subsistem morfologi, subsistem sintaksis, dan subsistem semantik." Pendapat ini sejalan dengan pendapat Pateda (1994:55) bahwa, "Tataran bahasa mencakup fonologi, morfologi, sintaksis, dan semantik."

Morfologi merupakan cabang linguistik yang mengidentifikasi satuansatuan dasar bahasa sebagai satuan gramatikal, morfologi juga mempelajari seluk beluk kata serta pengaruh perubahan-perubahan bentuk kata baik fungsi gramatikal maupun fungsi semantik. Rofii dan Franscy (2018:7) mengatakan bahwa in the morphology, described the process of word formation, said forming tool, class of words, meanings of words, as well as changes in the sound produced by the morphological process Menurut Pateda (1994:71), "Morfologi adalah ilmu yang mempelajari bentuk kata, serta makna yang muncul akibat perubahan bentuk itu." Pendapat ini menjelaskan bahwa morfologi merupakan ilmu bahasa yang mempelajari bentuk dan makna kata yang muncul dari perubahan terhadap bentuk bahasa itu sendiri.

$$
\text { Menurut Chaer (2015:3), }
$$

"Morfologi berarti ilmu mengenai bentuk-bentuk dan pembentukan kata." Pendapat ini lebih singkat dijelaskan bahwa morfologi membicarakan dan mempelajari masalah bentuk kata dan pembentukan kata yang terdapat di dalam suatu bahasa. Sementara itu, menurut Ramlan (2009:21), "Morfologi mempelajari seluk-beluk kata serta fungsi perubahan-perubahan bentuk kata itu, baik fungsi gramatik maupun fungsi semantik." Dalam morfologi juga dipelajari proses morfologis (Rofii dan Franscy, 2016). Berdasarkan pendapat 
para ahli di atas, maka dapat disimpulkan bahwa morfologi merupakan ilmu bahasa yang mempelajari tentang seluk beluk bentuk, fungsi, dan makna kata di dalam bahasa itu sendiri.

Chaer (2015:63), berpendapat bahwa "Kata merupakan bentuk yang, ke dalam mempunyai susunan fonologi yang stabil dan tidak berubah, dan ke luar mempunyai kemungkinan mobilitas di dalam kalimat". Secara tradisional kata dijelaskan sebagai kumpulan huruf yang mengandung arti. Jadi setiap kata tentu mengandung arti ((Tardjan Hadidjaja, 1963:19; S. Zainuddin, 1956:39) dalam Ramlan, 1991:5) (Rofii, 2016)”.

Menurut Ramlan (2009:33), "Kata ialah bentuk bebas yang paling sedikit atau dengan kata lain setiap suatu bentuk bebas merupakan suatu kata." Bagi Ramlan ciri utama untuk mengatakan suatu bentuk adalah kata atau tidak, yakni sifat "kebebasannya". Menurut Lyons (dalam Suhardi 2013: 87) "Kata merupakan persatuan makna tertentu dengan susunan bunyi tertentu, dapat dipakai menurut tata bahasa dengan cara tertentu." Hal ini disebabkan kata merupakan sebuah satuan semantis, fonologis, dan gramatikal.

Kelas kata merupakan pembagian kata menurut bentuk, jenis dan makna yang ada di dalam kata untuk membentuk sebuah kalimat. Menurut Kridalaksana (1990:41), "Kelas kata atau (jenis kata) adalah perangkat kata yang sedikit banyak berperilaku sintaksis sama". Berdasarkan pendapat tersebut, dapat disimpulkan bahwa kelas kata merupakan pembangian terhadap kata dalam bahasa yang didasari oleh bentuk, fungsi dan makna sesuai tata bahasa tersebut.

Kridalaksana

(1990:49-118), menggolongkan kata bahasa Indonesia menjadi 13 (tiga belas) kelas kata yaitu (1) verba, (2) ajektiva, (3) nomina, (4) pronomina, (5) adverbia, (6) numeralia, (7) interogativa, (8) demonstrativa, (9) artikula, (10) preposisi, (11) konjungsi, (12) kategori fatis, dan (13) interjeksi." Selanjutnya, menurut Alwi dkk. (dalam Muslich 2010: 121), menggolongkan kata menjadi 7 kelas kata yaitu (1) verba, (2) nomina, (3) pronomina, (4) numeralia, (5) ajektiva, (6) adverbia, (7) kata tugas."

Adverbia merupakan salah satu bagian dari kelas kata, yang menjadi kata keterangan di dalam sebuah kalimat. Menurut Chaer (2015:83), "Adverbia disebut sebagai kata-kata yang bertugas mendampingi nomina, verba, dan ajektiva". Adverbia inilah yang dijadikan dasar kriteria untuk menentukan katakata berkelas nomina, verba, atau ajektiva. Adverbia biasa disebut dengan kata keterangan atau kata keterangan tambahan, yang fungsinya adalah menerangkan kata kerja, kata sifat, dan jenis tambahan lainnya.

Menurut Alwi dkk (1993: 218), "Adverbia adalah kata yang digunakan untuk menerangkan unsur atau bagian kalimat yang berfungsi sebagai predikat, baik berupa verba, adjektiva, nomina, maupun numeralia." Adverbia harus dibedakan dari keterangan sebagai fungsionaris kalimat perhatikanlah pemakaian kata segera, sangat, hanya, dan hampir pada kalimat ini: Dia segera pergi, dalam kalimat ini kata segera adalah advebia yang menerangkan verba pergi. Pendapat ini menjelaskan bahwa adverbia adalah kata yang digunakan untuk menerangkan suatu unsur kata atau bagian kalimat dan fungsinya sebagai predikat atau bagian kalimat yang menandai apa yang dikatakan oleh subjek.

Selanjutnya, menurut Kridalaksana (1990:79), “Adverbia adalah kategori yang mendampingi ajektiva, numeralia, atau preposisi dalam 
konstruksi sintaksis."Pendapat ini menyatakan bahwa adverbia merupakan jenis kata yang mendampingi kata ajektiva, numeralia, atau preposisi dalam sebuah kalimat.

Djajasudarma

(2010:45) menyatakan bahwa, "Adverbia adalah unsur bahasa yang menerangkan verba pada umunya, sebagian adjektiva, dan adverbia itu sendiri." Adverbia cenderung merupakan kategori yang mendampingi preposisi atau kata depan dalam kalimat. Menurut Widjono (2007:136), "Adverbia adalah kata yang memberi keterangan pada verba, adjektiva, nomina predikatif, atau kalimat." Berdasarkan beberapa penjelasan yang dikemukakan dalam uraian di atas, maka dapat disimpulkan bahwa adverbia merupakan kata yang memberi keterangan pada kata di dalam suatu kalimat, yang berfungsi sebagai predikat atau bagian kalimat yang menandai apa yang dikatakan oleh subjek.

Berdasarkan dari segi perilaku sintaksisnya menurut Alwi dkk. (1993:222-223) adverbia dapat dilihat berdasarkan letak struktur dan lingkup strukturnya. "Dari segi letak strukturnya dapat diamati perilaku adverbia (a) senantiasa mendahului kata yang diterangkan, seperti lebih, terlalu, sempat, dan hanya, (b) senantiasa mengikuti kata yang diterangkan, seperti nian, benar, saja, dan sekali, dan (c) dapat mendahului atau mengikuti kata yang diterangkan, seperti selalu dan segera."

Menurut alwi dkk. (1993: 222-223) berdasarkan segi lingkup strukturnya dapat ditinjau medan jangkauan adverbia yang terbatas pada satuan frasa dan yang mencapai satuan kalimat. "Adverbia yang jangkauannya terbatas pada frasa terdapat pada frasa adjektival, frasa verbal, frasa adverbial, dan frasa nominal predikatif."
Lingkup strukturnya menjangkau satuan kalimat atau yang memberi keterangan pada klausa dinyatakan oleh bentuk polimorfemis.

Menurut Kridalaksana (1990:8182), adverbia dari segi perilaku sintaksisnya dapat dibedakan menjadi 2 (dua) subkategori yaitu adverbial intrakalusal dan adverbial ekstraklausal.

1. Adverbia intraklausal, ialah adverbia yang berkonstruksi dengan verba, ajektiva, numeralia, atau adverbia lainya. Misalnya, alangkah, agakagak, amat sangat, dan sebagainya.

2. Adverbia ekstraklausal ialah adverbia yagng secara sintaksis mempunyai kemungkinan untuk berpindah-pindah posisi dan secara semantik mengungkapkan perihal atau tingkat proposisi secara keseluruhan. Misalnya, barangkali, bukan, justru, memang dan mungkin.

Berdasarkan pendapat para ahli di tersebut, maka dapat disimpulkan bahwa masing-masing pendapat mempunyai 2 perbedaan terkait adverbia dari segi perilaku sintaksisnya yaitu adverbia intraklausal dan adverbia ekstraklausal. Maka yang perlu diperhatikan sehubungan dengan perbedaan dari keduanya ialah unsur atau bagian kalimat yang diacu oleh adverbia yang bersangkutan. Adverbia intraklausal mengacu pada frasa dan adverbia ekstraklausal mengacu pada kalimat, meskipun posisi sintaksisnya mengalami perubahan.

Sintaksis merupakan cabang ilmu dari tataran bahasa, mengkaji kata lebih luas dari morfologi. Menurut Ramlan (1982:1), "Sintaksis ialah bagian cabang ilmu bahasa yang membicarakan seluk beluk wacana, kalimat, klausa, dan frase."Pendapat ini menjelaskan bahwa sintaksis merupakan cabang ilmu bahasa 
yang mempelajari segala sesuatu tentang wacana, kalimat, klausa, dan frase.

Menurut Chaer (2012:206), "Sintaksis bidang tataran linguistik atau tata bahasa yang membicarakan kata dalam hubungannya dengan kata lain, atau unsur-unsur lain sebagai suatu ujaran." Sementara itu, Crystal (dalam Putrayasa 2017:2), menyatakan bahwa, "Sintaksis sebagai studi tentang kaidahkaidah pembentukan kalimat dan gabungan kata-kata dalam sebuah bahasa." Berdasarkan pendapat di atas dapat dikatakan sintaksis merupakan cabang ilmu linguistik atau bahasa yang mempelajari dan membahas tentang kaidah-kaidah pembentukan kalimat dan hubungan antarkata dalam ujaran. Berdasarkan pendapat ahli tersebut, dapat disimpulkan bahwa sintaksis merupakan tata bahasa yang mempelajari tentang seluk beluk wacana, kalimat, klausa, dan frase dan membicarakan kata dalam hubungannya dengan kata lain pada suatu ujaran atau bahasa.

\section{METODE PENELITIAN}

Pendekatan penelitian ini dipilih berdasarkan kesesuaian terhadap objek dan tujuan penelitian. Dalam penelitian ini, metode yang digunakan deskriptif kualitatif. Martha dan Kresno (2016: 1) menyatakan bahwa, "Penelitian kualitatif merupakan jenis penelitian yang menghasilkan penemuan-penemuan yang tidak diperoleh dengan menggunakan prosedur statistik." Menurut Patton (dalam Ahmadi 2016: 15), "Penelitian kualitatif adalah metode untuk memahami fenomena yang sedang terjadi secara alamiah (natural) dalam keadaankeadaan yang sedang terjadi secara alamiah. Data alamiah yang dihasilkan berupa ungkapan langsung dari subjek peneliti dengan mengajukan seperangkat pertanyaan oleh peneliti kepada subjek (narasumber).

Subjek penelitian merupakan orang yang diminta untuk memberikan keterangan tentang fakta atau pendapat. Adapun subjek penelitian ini adalah seluruh masyarakat di Kelurahan Tanjung Raden Kecamatan Danau Teluk Kota Jambi.

Menurut Mahsun (2006:70), "Bahan atau materi penelitian dapat berupa uraian tentang populasi dan sampel penelitian,serta informan. Populasi, sampel, dan informan haruslah dijelaskan secara spesifik, termasuk menyebutkan dengan jelas sifat dan kategori populasi, sampel, dan responden penelitian. Sampel penelitian dapat berupa lokasi atau daerah pemukiman pemakai bahasa tertentu." Subjek penelitian di dalam penelitian ini adalah beberapa orang informan (sampel) yaitu 1 orang sampel di bagian barat, 1 orang sampel bagian timur, 1 orang bagian selatan, 1 orang bagian utara, 2 orang di bagian tengah (pusat) penelitian di Kelurahan Tanjung Raden Kecamatan Danau Teluk Kota Jambi, dengan jumlah sampel 6 orang. Djajasudarma (2010: 22) menyatakan bahwa, "Informan dapat pula ditentukan jumlahnya berdasarkan arah mata angin (4 samapai 6 orang) ditambah dengan lokasi pusat (1 sampai 2 orang)." Hal ini sesuai dengan dengan arah mata angin (4 sampai 6 orang) ditambah dengan lokasi pusat (1 sampai 2 orang).

Data primer merupakan data utama dalam penelitian ini. Menurut Iskandar (2008: 76), "Data primer merupakan data yang diperoleh melalui serangkaian kegiatan." Data primer diperoleh dengan cara berhubungan langsung dengan objek yang akan diteliti dalam suatu penelitian. Data primer dalam peneltian ini berupa bahasa lisan dari hasil wawancara peneliti mengenai 
bentuk dan ciri adverbia bahasa Melayu Jambi di Kelurahan Tanjung Raden Kecamatan Danau Teluk Kota Jambi.

Data sekunder merupakan data pendukung. Menurut Iskandar (2008: 77), "Data sekunder merupakan data yang diperoleh melalui pengumpulan atau pengolahan data yang bersifat studi dokumentasi berupa penelaah terhadap dokumen pribadi, resmi kelembagaan, referensiliteratur laporan, dan lain-lain yang memiliki relevansi dengan fokus permasalah penelitian." Data sekunder berupa informasi atau keterangan latar belakang sosial budaya dan situasional sebagai hasil pengamatan dan wawancara. Data sekunder dalam penelitian ini merupakan data pelengkap yang diperoleh dari studi pustaka, data pelengkap diperoleh dari buku-buku yang berhubungan dengan teori adverbia bahasa Melayu Jambi yang akan digunakan dalam penelitian ini.

Sumber data dalam penelitian kualitatif adalah tindakan, kata-kata, serta dokumen atau literatur-literatur. Dalam penelitian ini, data bersumber dari 6 informan yang telah ditentukan.

Pengumpulan data dalam penelitian ini dilakukan melalui observasi, dan wawancara. Menurut Hadi (dalam Sugiyono 2007: 203) "Observasi merupakan suatu proses yang kompleks, suatu proses yang tersusun dari pelbagai proses biologis dan psikhologis. Dua di antara yang terpenting adalah prosesproses pengamatan dan ingatan. Metode observasi merupakan teknik pengumpulan data yang berdasarkan pengamatan atau meninjau langsung dilapangan. Peneliti menggunakan metode ini untuk melakukan pengamatan- secara langsung terhadap penggunaan adverbia bahasa Malayu Jambi di Kelurahan Tanjung Raden Kecamatan Danau Teluk Kota Jambi.
Menurut Danim (2002: 130), "Wawancara merupakan sebuah percakapan antara dua orang atau lebih, yang pertanyaannya diajukan oleh peneliti kepada subjek atau sekelompok subjek peneliti untuk dijawab." Metode wawancara ini merupakan teknik yang dilakukan dengan cara dialog kecil antara peneliti dan informan untuk mendapatkan data yang akan diteliti. Dalam penelitian ini peneliti melakukan wawancara untuk mendapatkan data atau hasil wawancara dari penutur mengenai adverbia bahasa Melayu Jambi di Kelurahan Tanjung Raden Kecamatan Danau Teluk Kota Jambi. Mahsun (2006: 111) menyatakan bahwa, "Analisis data merupakan tahapan yang sangat menentukan, karena pada tahap ini kaidah-kaidah yang mengatur keberadaan objek penelitian harus sudah diperoleh."

Teknik analisis data dalam penelitian ini menggunakan metode agih atau metode distribusional untuk mengolah data yang telah diperoleh. Djajasudarma (2010: 69) menyatakan bahwa, "Metode kajian distibusional menggunakan alat penentu unsur bahasa itu sendiri."Menurut Muhammad (2011: 244), "Metode agih merupakan kebalikan dari metode padan berdasarkan alat penentunya. Alat penentu untuk memilah unsur bahasa yang ada di dalam bahasa, bankan menyatu dengan datanya."Menurut Sudaryanto (dalam Rahayu 2013:5), "Dasar penentuan di dalam kerja metode Distribusional adalah teknik-teknik pemilihan data berdasarkan kategori atau kriteria tertentu dari segi kegramatikkan sesuai dengan ciri-ciri alami yang dimiliki oleh data penelitian.".

Menurut Mathinson (dalam Sugiyono 2007: 332) "Nilai dari teknik pengumpulan data dengan triangulasi adalah untuk mengetahui data yang 
diperoleh meluas, tidak konsisten atau kontradiksi atau pertentangan antara dua hal." Berdasarkan pendapat di atas, dapat disimpulkan bahwa triangulasi dipakai untuk menguji dan mengecek ulang validitas data yang telah dikumpulkan. Dalam penelitian ini, data diabsahkan menggunakan triangulasi, yaitu berdasarkan arahan dan konsultasi ke pembimbing skripsi dalam melakukan penelitian.

\section{HASIL DAN PEMBAHASAN}

Berdasarkan hasil penelitian, pertanyaan penelitian, dan analisis data penelitian. dijelaskan hasil penelitian tentang adverbia bahasa Melayu Jambi di Kelurahan Tanjung Raden Kecamatan Danau Teluk Kota Jambi. Subjek dalam penelitian ini adalah masyarakat penutur asli di Kelurahan Tanjung Raden yang menggunakan bahasa Melayu Jambi dalam betutur sapa ketika berkomunikasi. Berikut dikemukakan hasil penelitian yang mencakup ciri-ciri adverbia yakni: 1) Ciri-ciri adverbia dari aspek morfologi bahasa Melayu Jambi di Kelurahan Tanjung Raden sebanyak 33 data yang termasuk ciri morfologi dari 68 data yang ada. 2) Cir-ciri adverbia dari aspek sintaksis bahasa Melayu Jambi di Kelurahan Tanjung Raden Kecamatan Danau Teluk Kota Jambi sebanyak 64 data yang termasuk ciri sintaksis dari 68 data yang ada.

\section{Ciri-ciri Adverbia dari Aspek Morfologi Bahasa Melayu Jambi di Kelurahan Tanjung Raden Kecamatan Danau Teluk Kota Jambi}

Suatu kata yang termasuk dalam ciri adverbia dari aspek morfologi akan mengalami proses morfologi dari bentuk kata sebelumnya atau dari bentuk kata dasar. "Morfologi mempelajari selukbeluk kata serta fungsi perubahan- perubahan bentuk kata itu, baik fungsi gramatik maupun fungsi semantik" (Ramlan, 2009: 21). Muslich (2010: 32) menyatakan bahwa, "Morfem-morfem yang menjadi anggota kata ini mengalami peristiwa pembentukan sebelumnya". Berdasarkan teori Alwi dkk. (1993), Kridalaksana (1990) dan Muslich (2010) yang dijadikan patokan analisis, maka diidentifikasi ciri morfologi yang terdiri dari 2 data.

1. Ciri adverbia bahasa Melayu Jambi di Kelurahan Tanjung Raden Kecamatan Danau Teluk Kota Jambi yang tergolong ciri morfologi seperti kata 'moyo' yang berarti 'tidak' dapat memiliki ciri morfologi di dalam sebuah kalimat, karena 'moyo' merupakan kata dasar dan bisa berpotensi atau bergabung dengan partikel se-, -nya, dan bisa mengalami proses pengulangan kata dasar yang masih termasuk golongan adverbia. Contoh kata adverbia 'moyo' di dalam kalimat: moknga yanti (moyo) pegi ke yasinan. Hal tersebut mengacu teori Alwi (1993: 220) dan Muslich (2010: 33) tentang proses morfologis.

2. Ciri adverbia bahasa Melayu Jambi di Kelurahan Tanjung Raden Kecamatan Danau Teluk Kota Jambi yang tergolong tidak terdapat ciri morfologi ialah seperti kata 'kenyok' yang berarti "hanya' tidak memiliki ciri morfologi di dalam sebuah kalimat, karena kata 'kenyok' tidak menunjukkan ciri suatu kata yang mengalami proses morfologis atau tidak dapat bergabung dengan partikel afiksasi, karena apabila mengalami proses morfologis kata 'kenyok' tidak termasuk ke dalam golongan adverbia lagi. Contoh kata adverbia 'kenyok' di dalam kalimat: Tik (kenyok) baju dengat tu punyo kau. 
Ciri-ciri Adverbia dari Aspek Sintaksis Bahasa Melayu Jambi di Kelurahan Tanjung Raden Kecamatan Danau Teluk Kota Jambi

Berdasarkan dari segi perilaku sintaksisnya adverbia dapat dilihat berdasarkan letak struktur dan lingkup strukturnya. Menurut Alwi dkk. (1993: 222-223), "Dari segi letak strukturnya dapat diamati perilaku adverbia (a) senantiasa mendahului kata yang diterangkan, (b) senantiasa mengikuti kata yang diterangkan dan (c) dapat mendahului atau mengikuti kata yang diterangkan." Berdasarkan teori Alwi dkk. (1993), Kridalaksana (1990) dan Muslich (2010) yang dijadikan patokan analisis, maka diidentifikasi ciri adverbia dari aspek sintaksis yang terdiri dari 2 data. Sebagaimana dijelaskan pada bagian berikut ini.

1. Ciri adverbia sintaksis di Kelurahan Tanjung Raden Kecamatan Danau Teluk Kota Jambi yang tergolong ciri adverbia sintaksis seperti kata ' $b e$ ' yang berarti 'saja' dapat dijadikan sebagai ciri sintaksis di dalam sebuah kalimat, karena kata 'be' merupakan adverbia yang posisinya ada setelah kata yang hendak diterangkan oleh adverbia tersebut, contoh kata adverbia ' $b e$ ' di dalam kalimat: Perasoan sayo baju ko (be) yang kau pakek. Hal ini mengacu pada pendapat Alwi dkk. (1993 :222) yang mengatakan, bahwa dari segi letak strukturnya dapat diamati perilaku adverbia (b) senantiasa mengikuti kata yang diterangkan.

2. Ciri adverbia sintaksis di Kelurahan Tanjung Raden Kecamatan Danau Teluk Kota Jambi yang tidak tergolong ciri adverbia sintaksis seperti kata 'dedewek' yang berarti "sendiri-sendiri" tidak dapat dijadikan sebagai ciri sintaksis di dalam sebuah kalimat, karena kata 'dedewek' merupakan adverbia yang hendak diterangkan oleh adverbia tersebut. Contoh kata 'dedewek'di dalam kalimat: (dedewek) be kau di siko Fandi. Kata 'dedewek' dalam kalimat ini telah menjelaskan kata yang diterangkan di dalam kalimat tersebut.

\section{SIMPULAN}

Berdasarkan hasil penelitian dan pembahasan maka dapat di simpulkan bahwa terdapat 68 data bentuk dan ciri adverbia bahasa Melayu Jambi di Kelurahan Tanjung Raden Kecamatan Danau Teluk Kota Jambi.

Ciri adverbia dari aspek morfologi yang dominan terdiri atas ciri yang tidak terdapat adverbia morfologi sebanyak 36 data misalnya kata 'lah' yang artinya sudah, dan ' $b e$ ' yang artinya “". Selanjutnya, ciri adverbia sintaksis yang dominan terdiri dari ciri yang terdapat adverbia sintaksis sebanyak 64 data misalnya kata 'hamper' yang artinya hampir, 'hanyo' yang artinya hanyo, dan 'nian' yang artinya 'sekali'.

\section{Rekomendasi}

1. Bagi masyarakat penutur asli Melayu Jambi diharapkan dapat melestarikan dan mempertahankan bahasa Melayu Jambi di Kelurahan Tanjung Raden Kecamatan Danau Teluk Kota Jambi.

2. Bagi peneliti ataupun pihak-pihak yang ingin melakukan penelitian serupa, hasil penelitian ini dapat dijadikan sebagai acuan dalam melakukan penelitian selanjutnya.

3. Bagi Guru, maupun dosen, hasil penelitian ini dapat dijadikan sebagai alternatif bahan ajar dalam pembelajaran tentang bahasa daerah Melayu Jambi di Kelurahan Tanjung Raden Kecamatan Danau Teluk Kota Jambi. 
4. Bagi pemerintahan dapat membuat kebijakan tentang bahasa Melayu Jambi untuk pengembangan bahasa daerah.

\section{DAFTAR PUSTAKA}

Adwin, M. Jul. (2013). Pemertahanan Bahasa Melayu Jambi Dialek Seberang di Kota Jambi. Skripsi. Jambi: Universitas Batanghari.

Ahmadi, Rulam. (2016). Metodologi Penelitian Kualitatif. Yogyakarta: Ar-Ruzz Media.

Alwi, Hasan dkk. (1993). Tata Bahasa Baku Bahasa Indonesia. Pusat Bahasa: Departemen Pendidikan dan Kebudayaan Republik Indonesia.

Chaer, Abdul. (2011). Tata Bahasa Praktis Bahasa Indonesia. Jakarta: Rineka Cipta.

Chaer, Abdul. (2012). Lingustik Umum. Jakarta: Rineka Cipta.

Chaer, Abdul. (2015). Morfologi Bahasa Indonesia (Pendekatan Proses). Jakarta: Rineka Cipta.

Chaer, Abdul. (2015). Sintaksis Bahasa Indonesia. Jakarta: Rineka Cipta.

Danim, Sudarwan. (2002). Menjadi Peneliti Kualitatif. Bandung: CV. Pustaka Setia.

Djajasudarma, Fatimah. (2010). Metoda Lingistik: Ancangan Metode Penelitian dan Kajian. Bandung: PT Refika Aditama.

Husin, Nurzuir dkk. (1986). Morfosintaksis Bahasa Melayu Jambi. Jakarta: Pusat Pembinaan dan Pengembangan Bahasa Departemen Pendidikan dan Kebudayaan.
Iskandar. (2008). Metodologi Penelitian Pendidikan dan Sosial (Kuantitatif dan Kualitatif). Jakarta: GP Press.

Kridalaksana, Harimurti. (1990). Kelas Kata dalam Bahasa Indonesia. Jakarta: PT Gramedia.

Mahsun. (2006). Metode Penelitian Bahasa. Jakarta: PT RajaGrafindo Persada.

Martha, Evi dan Kresno, Sudarti. (2016). Metodologi Penelitian Kualitatif untuk Bidang Kesehatan. Jakarta: PT RajaGrafindo Persada.

Muhammad. (2011). Metode Penelitian Bahasa. Yogyakarta: Ar-Ruzz Media.

Muslich, Masnur. (2010). Tata Bentuk Bahasa Indonesia Kajian Kajian ke Arah Tata Bahasa Deskritif. Jakarta: Bumi Aksara.

Parera, Jos Daniel. (1987). Studi Linguistik Umum dan Historis Bandingan. Jakarta: Penerbit Erlangga.

Pateda, Mansoer. (1994). Linguistik Sebuah Pengantar. Gorontalo: Angkasa.

Putrayasa, Ida Bagus. (2017). Sintaksis Memahami Kalimat Tunggal. Bandung: Refika Aditama.

Rahayu, Actri Putri. (2012). http://repository.upi.edu/8748/4/s _jep_0807395_chapter3.pdf(diaks es pada 19 Januari 2019 pukul $20.00 \mathrm{WIB})$

Rahima, A. (2002). Sistem sapaan bahasa Melayu Jambi: laporan penelitian. Fakultas Keguruan dan Ilmu Pendidikan, Universitas Batanghari. 
Ramlan, M. (1991). Tata Bahasa Indonesia Penggolongan Kata. Yogyakarta: Andi Offset.

Ramlan, M. (2009). Morfologi Suatu Tinjauan Deskriptif. Yogyakarta: CV. Karyono.

Ramlan, M.. (1982). Sintaksis. Yogyakarta: CV. Karyono.

Rofii, Afif. (2016) An Analysis of Syntactical Ability of Second Language Children Age 5-6 Years Old in Taman Kanak-Kanak (TK) Para Bintang Kota Jambi. Jurnal Ilmiah Dikdaya, Vol. 06, Nomor 1 2016.http://dikdaya.unbari.ac.id/in dex.php/dikdaya/article/view/38

Rofii, Afif. dan Franscy. (2016). The Development of ContextualBased Texbook on Morphological Process in Faculty of Teachers Training and Education Batanghari University Jambi. The Asian EFL Journal. Volume 1 Issue 2 Juli 2018. ISSN 1738$1460 . \quad$ http://.asian-efljournal.com/9921/tesol indonesiaconference-

2016/2016/12/indonesianinternational-conference-editiondecember-2016volume-1/

Rofii, Afif. dan Franscy. (2018). The Development of Contextual-Based Texbook on Morphological Process in Faculty of Teachers Training and Education Batanghari University Jambi. The Asian ESP Journal. Volume 14 Issue 2 Juli 2018. ISSN 22060979. https://www.asian-espjournal.com/2018/volume-14issue-2-july-2018/

Rofii, Afif. dan Hasibuan, Rizka Rani (2019). Interferensi Bahasa Batak Mandailing dalam Tuturan Berbahasa Indonesia pada Acara
Parpunguan Masyarakat Mandailing Kota Jambi. Aksara: Jurnal Ilmiah Pendidikan Bahasa dan Sastra Indonesia Vol. 3 No. 12019. aksara.unbari.ac.id/index.php/aksa $\mathrm{ra} /$ article/download/94/50

Siswantoro. (2010). Metode Penelitian Sastra Analisis Struktur Puisi. Yogyakarta: Pustaka Belajar.

Sugiyono. (2007). Metode Penelitian Pendidikan. Bandung: Alfabeta.

Suhardi. (2013). Pengantar Linguistik

Umum. Yogyakarta: Ar-Ruzz Media.

Widjono. (2007). Bahasa Indonesia Mata Kuliah Pengembangan Kepribadian di Perguruan Tinggi. Jakarta: PT Grasindo. 